\title{
Influence of Monomer Structures on the High Temperature Properties of Poly[(Alkylamino)Borazine)]s Derived BN
}

\author{
Yongpeng Lei*, Yingde Wang and Yongcai Song
}

\author{
State Key Lab of Advanced Ceramic Fibers \& Composites, College of Aerospace and Materials Engineering, National \\ University of Defense Technology, Changsha 410073, P.R. China
}

\begin{abstract}
Preceramic polymers to boron nitride (BN) have been synthesized by thermal condensation of different (alkylamino)borazine monomers. Crystalline $\mathrm{BN}$ was obtained by pyrolysis of those polymeric precursors in $\mathrm{NH}_{3}$ and then in Ar. The influence of monomer structure on the chemical composition, microstructure, oxidation resistance and high temperature stability of BN was investigated by a combination of elemental analysis (EA), density measurement, FTIR, XPS, XRD, HRTEM and TGA. With similar chemical composition, BN derived from symmetric monomer exhibited a higher crystallinity, better oxidation resistance and higher temperature stability. This was because that the structure of the precursor polymerized from symmetric molecular was close to that of hexagonal BN $(h$-BN).
\end{abstract}

Keywords: Molecular structure, polymer-derived ceramics, microstructure, high temperature properties.

\section{INTRODUCTION}

Due to its high melting point, good thermal conductivity, high temperature stability and superior oxidation resistance, boron nitride $(\mathrm{BN})$ has been a potential non-oxide ceramic material for aircraft and space applications $[1,2]$. The most promising approach for the fabrication of shaped $\mathrm{BN}$ such as fiber, film, and mesoporous material is polymer-derived ceramics (PDCs) method [3-6]. Alkylaminoborazines (AAB) derived from 2,4,6-trichloroborazine (TCB) have been deemed to be attractive molecular monomers for processable polymers to BN in a complex form [7-9]. Nonetheless, as far as we know, it was not easy to synthesize $\mathrm{AAB}$ monomers to processable polymers due to the measurement of gaseous alkylamines [10].

Our attention has been focused on the synthesis of various monomers to melt-spinnable precursors using appropriate alkylamines and TCB without extraordinarily low temperature $[7,11]$. The reactivity of $\mathrm{AAB}$ monomers, which were in close connection with the processability of polymeric precursors, was strongly dependent on the substituent alkylamino groups linked with boron atoms [7, $10,12]$. However, the research that the structural influence of monomer on the poly[(alkylamino)borazine)]s derived BN's high temperature properties was limited, except that Toury et al. compared the crystallinity of $\mathrm{BN}$ from different molecular precursors [13]. Considering BN's excellent potential in structural/functional applications, it is necessary to investigate the high temperature properties of $\mathrm{BN}$ derived from various molecular monomers [14].

In this work, preceramic polymers were synthesized by thermal condensation of different (alkylamino)borazine monomers as reported by our own lab earlier [7, 11]. By

\footnotetext{
*Address correspondence to this author at the State Key Lab of Advanced Ceramic Fibers \& Composites, College of Aerospace \& Materials Engineering, National University of Defense Technology, Changsha 410073, China; Tel/Fax: +86 731 84575118; E-mail: lypkd@yahoo.com.cn
}

pyrolysis of the polymeric precursors under the same condition, nearly stoichiometric $\mathrm{BN}$ with similar composition but different microstructure and crystallinity were obtained. Oxidation behavior and high temperature stability of two BN sample were investigated. The difference in high temperature properties depends significantly on the crystallinity of $\mathrm{BN}$ originated from different (alkylamino)borazine monomers.

\section{EXPERIMENTAL}

All experiments were carried out in a nitrogen atmosphere using standard vacuum-line, Schlenk techniques and an efficient dry box with solvents purified by standard methods [15]. TGA was performed on a NETZSCH STA $449 \mathrm{C}$ instrument in $\mathrm{Ar}$ or air at a heating rate of $10{ }^{\circ} \mathrm{C} / \mathrm{min}$. Boron content was measured by a chemical titration method. Element contents of $\mathrm{N}, \mathrm{O}, \mathrm{H}$ and $\mathrm{C}$ were checked by Leco TCH-600 N/H/O and Leco CS-600 C/S analyzers. FTIR spectra were collected on a Nicolet Avatar 360 spectrophotometer as $\mathrm{KBr}$ pellets. XRD patterns were recorded using a powder X-ray diffractometer (Siemens D$5005, \mathrm{Cu} \mathrm{K}$ radiation). The average grain size was estimated by the Scherrer equation [16]. The XPS spectra were obtained using a VG ESCALAB MKП instrument ( $\mathrm{Al} \mathrm{K} \mathrm{K}_{\alpha}$ excitation). Density was measured by floatation in halogenated hydrocarbons. The HRTEM image was taken with a Philips CM 200 transmission electron microscope operated at $200 \mathrm{kV}$.

Molecular monomers TAB and PAB were synthesized by aminolysis reactions of 2,4,6-trichloroborazine (TCB) with iso-propylamine and $n$-propylamine/methylamine, respectively. PTAB and $\mathrm{PPAB}$ were prepared by thermal condensation of $\mathrm{TAB}$ and $\mathrm{PAB}$ described in our earlier work $[7,11]$. The molecular structures of monomers and polymers were shown in Table $\mathbf{1}$.

PTAB: FTIR $\left(\mathrm{KBr} / \mathrm{cm}^{-1}\right): 3421 / 3134 / 1031 \mathrm{~cm}^{-1}(\mathrm{~N}-\mathrm{H})$, 2924/2853 cm $\mathrm{cm}^{-1}$ (C-H), $1400 \mathrm{~cm}^{-1}$ (B-N), $745 \mathrm{~cm}^{-1}$ (B-N-B), $1078 \mathrm{~cm}^{-1}(\mathrm{C}-\mathrm{N}) \cdot{ }^{13} \mathrm{C}-\mathrm{NMR}(\mathrm{ppm}): \delta 8.9\left(-\mathrm{CH}_{3}\right), 25.9(-$ 
$\left.\mathrm{CH}_{2} \mathrm{CH}_{3}\right), 45.9\left(-\mathrm{NHCH}_{2}\right), 55.1\left(-\mathrm{NCH}_{2}\right)$. Elemental analysis (wt\%): B 23.13, C 22.67, N 44.70, O 0.97, H 8.33.

Table 1. Molecular Structure of the Monomers and Preceramic Polymers

\begin{tabular}{|c|c|c|}
\hline & Name & Chemical Structure \\
\hline \multirow{2}{*}{ Monomer } & TAB & 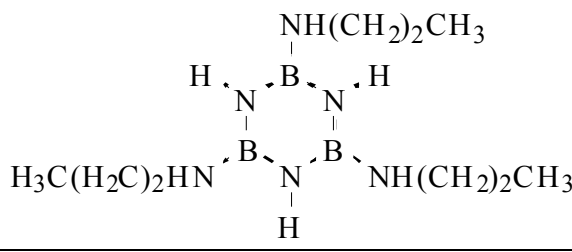 \\
\hline & PAB & 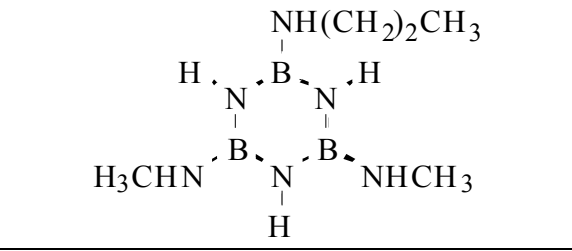 \\
\hline \multirow[t]{2}{*}{ Polymer } & PTAB & $\begin{array}{lll}\mathrm{H} & \mathrm{n} \\
& & \mathrm{N} \\
& & \left.\mathrm{C} \mathrm{CH}_{2}\right)_{2} \mathrm{CH}_{3}\end{array}$ \\
\hline & PPAB & 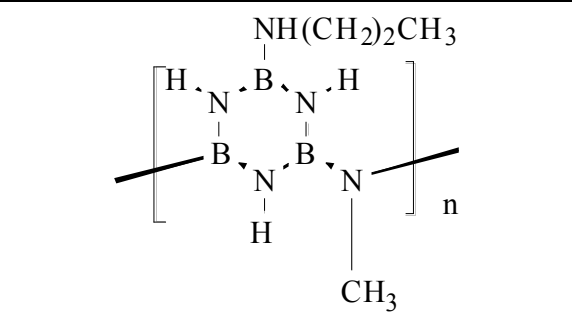 \\
\hline
\end{tabular}

PPAB: FTIR $\left(\mathrm{KBr} / \mathrm{cm}^{-1}\right): 3414 / 3130 / 1021 \mathrm{~cm}^{-1}(\mathrm{~N}-\mathrm{H})$, $2962 \mathrm{~cm}^{-1}$ (C-H), $1400 \mathrm{~cm}^{-1}$ (B-N), $805 \mathrm{~cm}^{-1}$ (B-N-B), 1092 $\mathrm{cm}^{-1}(\mathrm{C}-\mathrm{N}) \cdot{ }^{13} \mathrm{C}-\mathrm{NMR}(\mathrm{ppm}): \delta 19.3\left(-\mathrm{CH}_{3}\right), 43.4(-\mathrm{NHCH})$, 50.3 (-NCH-). Elemental analysis (wt\%): B 25.12, C 18.79, $\mathrm{N} 45.16, \mathrm{O} 0.82, \mathrm{H} 8.04$.

In a typical pyrolysis procedure, the polymer precursor lumps were milled using a tungsten carbide ball mill and sieved into particles in the size $<32 \mu \mathrm{m}$. Then the powders were weighed into an alumina boat and then placed in the pyrolysis tube. After purging the system with Ar for $30 \mathrm{~min}$, the samples were heated at $4{ }^{\circ} \mathrm{C} / \mathrm{min}$ to $1000{ }^{\circ} \mathrm{C}$ in $\mathrm{NH}_{3}(60$ $\mathrm{ml} / \mathrm{min}$ ) with a holding time of $2 \mathrm{~h}$ before cooling to ambient temperature naturally. Subsequently, the pyrolysis products were annealed under flowing $\mathrm{Ar}$ at $1500{ }^{\circ} \mathrm{C}$ in a graphite furnace with a holding time of $1 \mathrm{~h}$ (heating rate, $5^{\circ} \mathrm{C} / \mathrm{min}$ ).

\section{RESULTS AND DISCUSSION}

Fig. (1) displays the FTIR spectra of pyrolyzed samples from PTAB and PPAB at $1500{ }^{\circ} \mathrm{C}$ (called $\mathrm{BN}_{\mathrm{PTAB}}$ and $\mathrm{BN}_{\mathrm{PPAB}}$ ), which were almost the same. The very intense absorption at $1394 \mathrm{~cm}^{-1}$ and weak absorption at $804 \mathrm{~cm}^{-1} \mathrm{can}$ be assigned to the $v(\mathrm{~B}-\mathrm{N})$ and $\delta(\mathrm{B}-\mathrm{N}-\mathrm{B})$, respectively [17]. Moreover, the N-H band located around $3400 \mathrm{~cm}^{-1}$ indicated the presence of little residual hydrogen in the pyrolyzed samples.

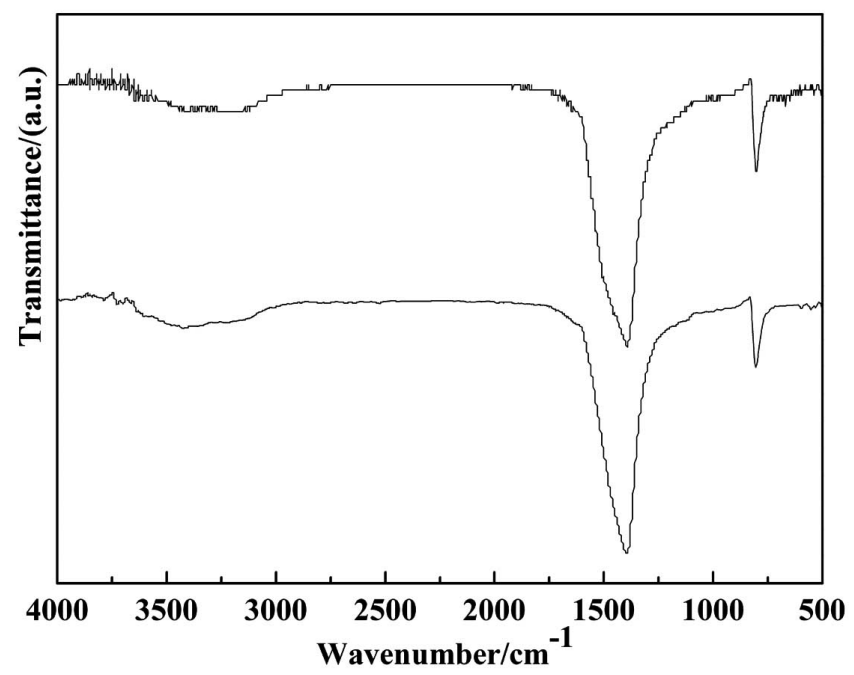

Fig. (1). FTIR spectra of pyrolyzed samples derived from (a) PTAB and (b) PPAB.

The chemical composition of the pyrolyzed products was investigated. The $\mathrm{B} / \mathrm{N}$ ratios of $\mathrm{BN}_{\mathrm{PTAB}}$ and $\mathrm{BN}_{\mathrm{PPAB}}$ at 1500 ${ }^{\circ} \mathrm{C}$ were $1: 1.07$ and $1: 1.05$ determined by EA, respectively. And carbon contents were both less than $0.2 \mathrm{wt} \%$, demonstrating the successful removal of carbon and preparation of nearly stoichiometric $\mathrm{BN}$ from alkylaminocontaining precursor. The densities for two $\mathrm{BN}$ samples were also similar, $1.81 \mathrm{~g} \cdot \mathrm{cm}^{-3}\left(\mathrm{BN}_{\mathrm{PPAB}}\right)$ and $1.85 \mathrm{~g} \cdot \mathrm{cm}^{-3}\left(\mathrm{BN}_{\mathrm{PPAB}}\right)$, respectively.

In order to further identify chemical bonding of the pyrolyzed products, XPS were conducted on two pyrolyzed products. The wide-scan XPS spectra of $\mathrm{BN}_{\mathrm{PTAB}}$ (Fig. 2a) indicated the presence of $\mathrm{B}, \mathrm{N}, \mathrm{C}$ and $\mathrm{O}$ element. The $\mathrm{C} 1 \mathrm{~s}$ signal may arise from different contamination. The presence of $\mathrm{O}$ element was mainly due to the absorption of oxygen species in form of $\mathrm{O}_{2}$ and $\mathrm{CO}_{2}$. The split $\mathrm{B} 1 \mathrm{~s}$ and $\mathrm{N} 1 \mathrm{~s}$ spectra of BN $\mathrm{BN}_{\mathrm{PTAB}}$ were shown in Fig. (2b, c). The B1s peak at $190.8 \mathrm{eV}$ and the $\mathrm{N} 1 \mathrm{~s}$ peak at $397.7 \mathrm{eV}$ indicated $\mathrm{BN}$, consistent with the previous reports on BN [18]. The XPS spectra of $\mathrm{BN}_{\mathrm{PPAB}}$ (not illustrated) were similar to that of $\mathrm{BN}_{\mathrm{PTAB}}$.

The Raman spectra of two pyrolyzed products were shown in Fig. (3). In Fig. (3a), the spectrum was typical of $h$ $\mathrm{BN}$ with a signal at $1374 \mathrm{~cm}^{-1}$. While in Fig. (3b), the large width of the band around $1500 \mathrm{~cm}^{-1}$ represented a noncrystalline $\mathrm{BN}$ [19]. The full width at half maximum (FWHM) was also much broader than that in $\mathrm{BN}_{\mathrm{PTAB}}$, indicating a lower crystallinity of the $\mathrm{BN}$ phase existed in $\mathrm{BN}_{\mathrm{PPAB}}$ [20]. The difference in crystallinity would be confirmed later on.

The crystalline structure of the $\mathrm{BN}$ phase was examined by XRD, as seen in Fig. (4). The FWHM of the (002) peak in $\mathrm{BN}_{\mathrm{PTAB}}$ was narrower than that in $\mathrm{BN}_{\mathrm{PPAB}}$, indicating a higher crystallinity and larger grain size. The peaks at $2 \theta=41.6^{\circ}, 43.5^{\circ}, 82.1^{\circ}$ in $\mathrm{BN}_{\mathrm{PTAB}}$ were ascribed to the (100), (110) and (112) planes, respectively. But yet (100) and (101) 


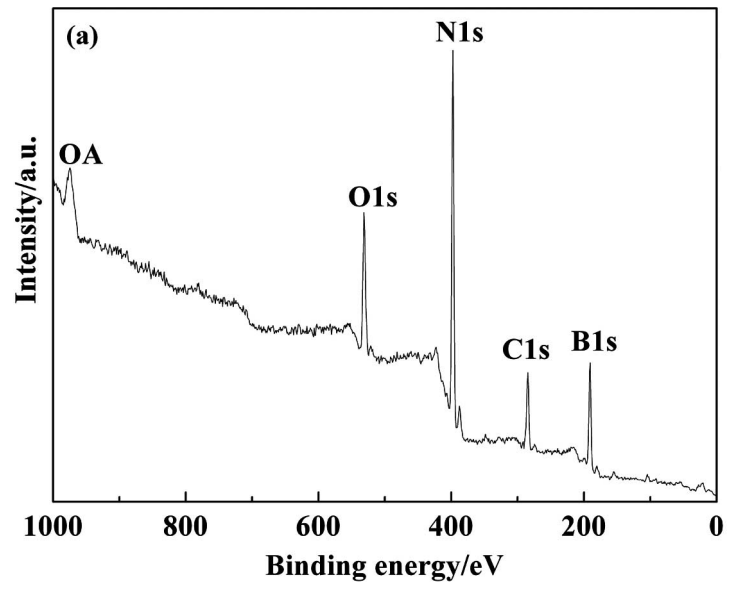

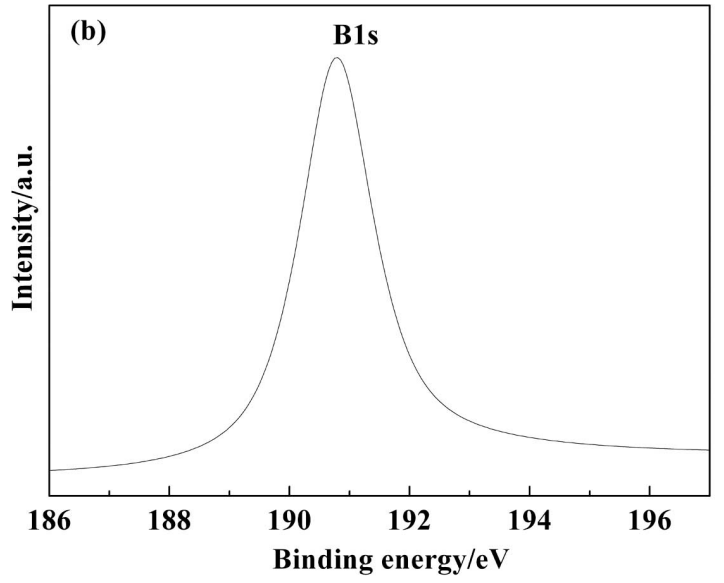

Fig. (2). XPS spectra of $\mathrm{BN}_{\mathrm{PTAB}}$ (a) wide-scan, (b) B1s and (c) N1s.

reflections in $\mathrm{BN}_{\mathrm{PPAB}}$ were indissociable and (112) was absent, suggesting the turbostratic character. Furthermore, the difference in the XRD patterns of those products further annealing at $1800{ }^{\circ} \mathrm{C}$ was more obvious. The samples annealing at $1800{ }^{\circ} \mathrm{C}$ derived from PTAB displayed a sharp (002) plane and other planes changed more evident compared to those obtained at $1500{ }^{\circ} \mathrm{C}$. While the XRD patterns of the residue from PTAB at $1800^{\circ} \mathrm{C}$ changed little.

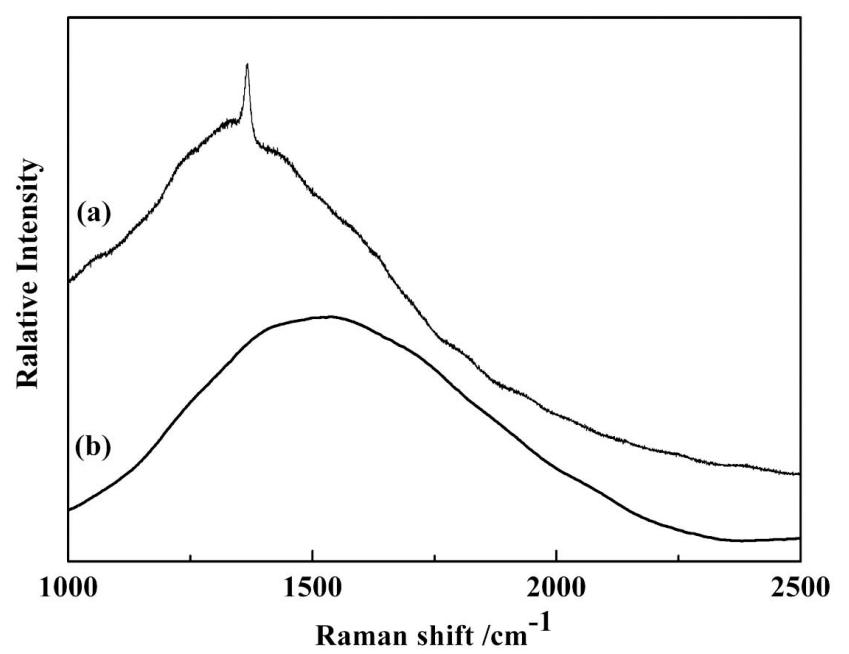

Fig. (3). Raman spectra of (a) $\mathrm{BN}_{\mathrm{PTAB}}$ and (b) $\mathrm{BN}_{\mathrm{PPAB}}$.
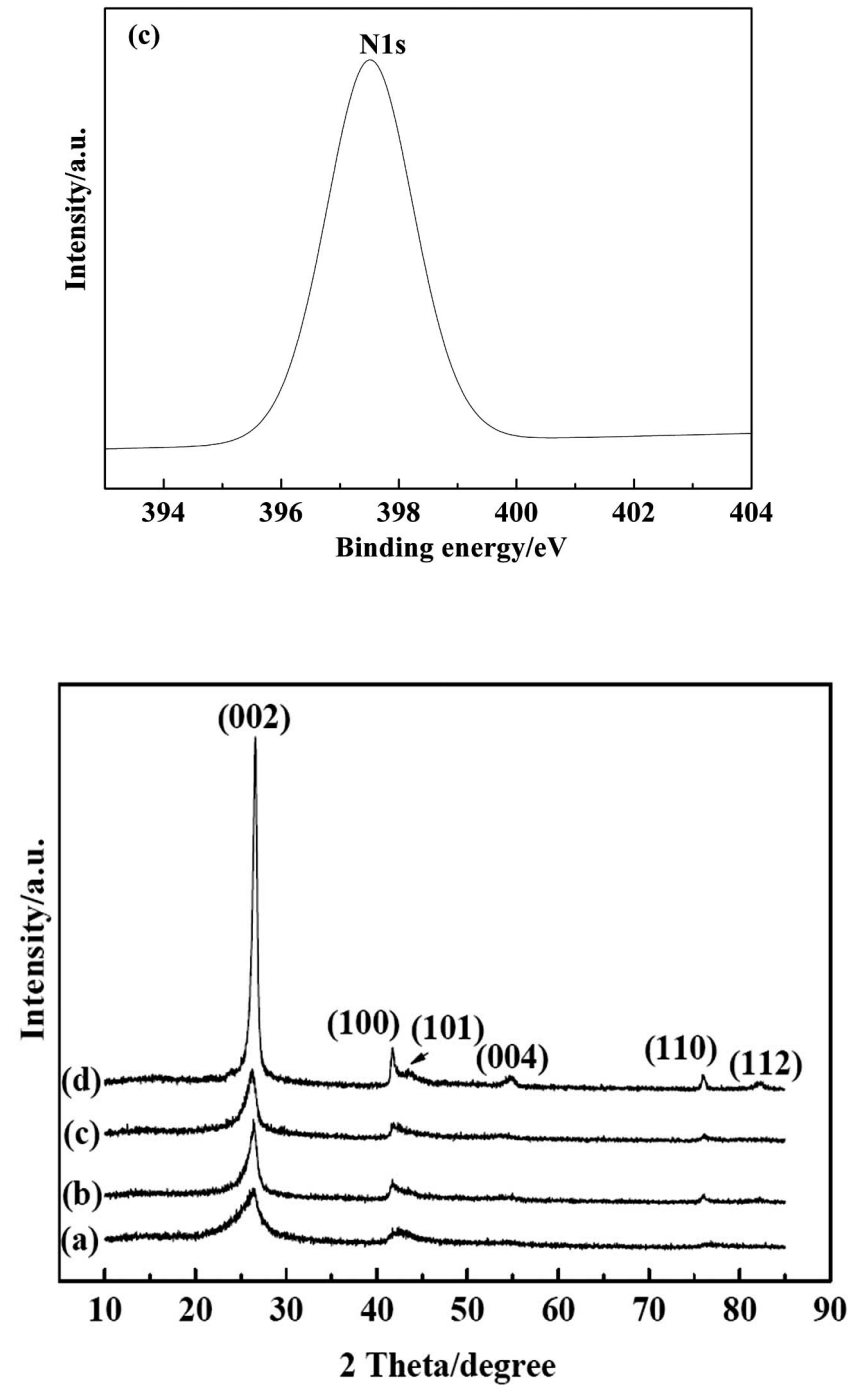

Fig. (4). XRD patterns of: (a, b) $\mathrm{BN}_{\mathrm{PPAB}}$ and $\mathrm{BN}_{\mathrm{PTAB}}$ obtained at $1500{ }^{\circ} \mathrm{C},(\mathbf{c}, \mathbf{d}) \mathrm{BN}_{\text {PPAB }}$ and $\mathrm{BN}_{\mathrm{PTAB}}$ at $1800^{\circ} \mathrm{C}$.

In addition, the average interlayer spacing $\left(d_{002}\right)$ and grain size $\left(L_{002}\right)$ were $3.36 \AA$ \& $/ 7.542 \mathrm{~nm}\left(\mathrm{BN}_{\mathrm{PTAB}}\right)$ and 3.40 $\AA / 5.320 \mathrm{~nm}\left(\mathrm{BN}_{\mathrm{PPAB}}\right)$ evaluated from the (002) diffraction, respectively. The results give a hint that symmetric molecular derived $\mathrm{BN}$ had a higher crystallinity over asymmetric molecular derived. Polymeric precursor whose 


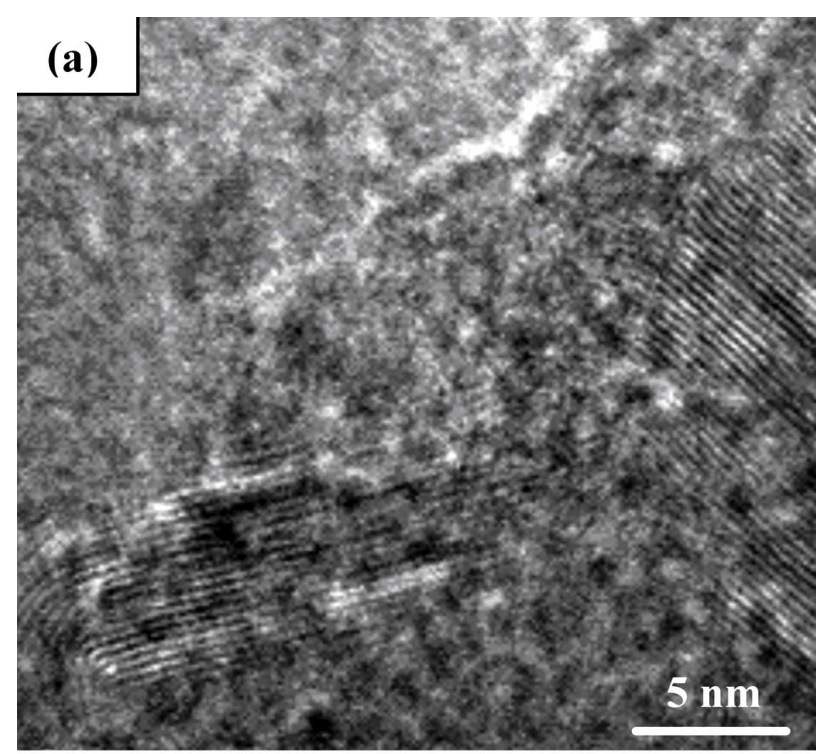

Fig. (5). HRTEM images of (a) $B N_{P T A B}$ and (b) $B N_{P P A B}$.

structure was closer to that of $h$-BN gave more-crystallized $\mathrm{BN}$, as Toury et al. studied [13]. PPAB was composed of $\mathrm{B}_{3} \mathrm{~N}_{3}$ rings most bonded through - $\mathrm{B}-\mathrm{N}\left(\mathrm{CH}_{3}\right)$-B- bridges. But yet, $\mathrm{B}_{3} \mathrm{~N}_{3}$ rings in $\mathrm{PTAB}$ were linked with more $-\mathrm{B}-\mathrm{N}-$ bridges and little -B-N $\left[\mathrm{CH}_{3}\left(\mathrm{CH}_{2}\right)_{2}\right]$-B- bridges, much closer to the structure of $h$-BN.

Further detailed investigation on the BN's microstructure was researched by HRTEM, as shown in Fig. (5). An important difference was noticed due to different crystallinity. In Fig. (5a), partially crystallized $\mathrm{BN}$ in some locally inhomogeneous regions was observed. While in Fig. (5b), a homogeneous amorphous phase was noticed [21]. This conclusion agrees well with that obtained from the XRD patterns.

Subsequently, the oxidation behaviors of two samples were studied under a flow of air at temperature up to 1000 ${ }^{\circ} \mathrm{C}$, as shown in Fig. (6). It is clear that $\mathrm{BN}_{\mathrm{PTAB}}$ showed an excellent stability with only a small detectable weight loss of $1.2 \mathrm{wt} \%$ at $900{ }^{\circ} \mathrm{C}$. In comparison, $\mathrm{BN}_{\mathrm{PPAB}}$ began to lose weight at around $270{ }^{\circ} \mathrm{C}$ and displayed a weight loss of 2.5 $\mathrm{wt} \%$ at $900{ }^{\circ} \mathrm{C}$. Furthermore, onset oxidation temperature for $\mathrm{BN}_{\mathrm{PTAB}}$ was a little higher than that for $\mathrm{BN}_{\mathrm{PPAB}}$. For two samples, the weight loss below $900{ }^{\circ} \mathrm{C}$ may be due to vaporization of $\mathrm{B}_{2} \mathrm{O}_{3}$ formed on the original surface of $\mathrm{BN}$ under normal room temperature [22]. Besides, $\mathrm{BN}_{\mathrm{PTAB}}$ showed a slower weight increase than $\mathrm{BN}_{\mathrm{PTAB}}$ above $900^{\circ} \mathrm{C}$. The weight increase was due to the formation of $\mathrm{B}_{2} \mathrm{O}_{3}$ according to eq.(1) and eq.(2) below. The discrepancy in oxidation rate between two $\mathrm{BN}$ samples was caused by different crystallinity that $\mathrm{BN}$ with a lower crystallinity showed a lower oxidation rate [23].

To investigate the high temperature stability of the asprepared $\mathrm{BN}$, the TGA experiment was carried out at temperature up to $1300{ }^{\circ} \mathrm{C}$ under flowing Ar. Fig. (7) displays the TGA curves of two samples. As expected, both $\mathrm{BN}$ presented good high-temperature stability up to $1300{ }^{\circ} \mathrm{C}$. A final weight loss of $1.4 \mathrm{wt} \%$ and $4.1 \mathrm{wt} \%$ were observed

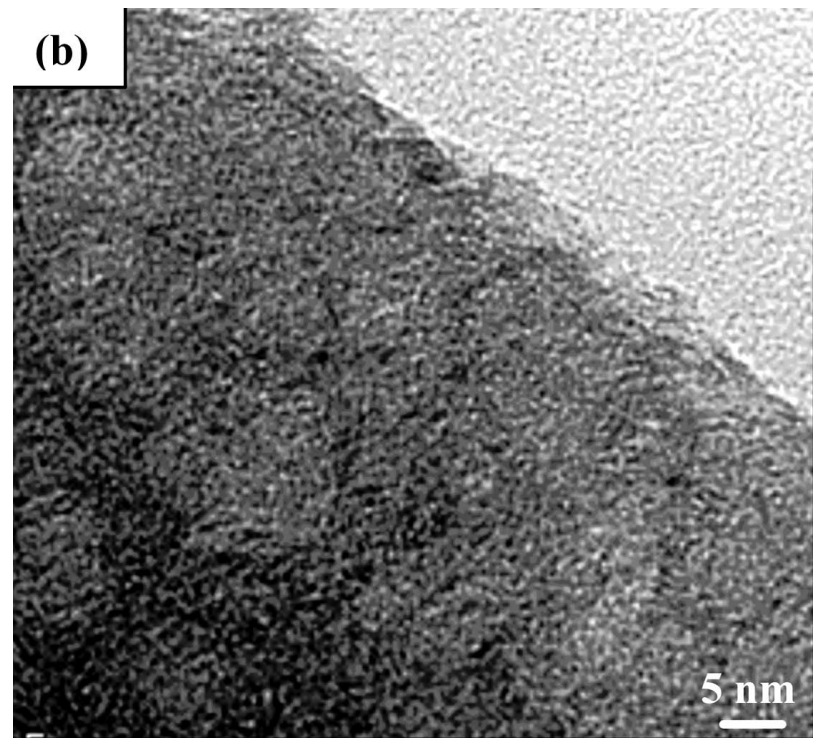

for $\mathrm{BN}_{\mathrm{PTAB}}$ and $\mathrm{BN}_{\mathrm{PPAB}}$, respectively, indicating a higher stability of $\mathrm{BN}_{\mathrm{PTAB}}$. The weight loss may also result from vaporization of $\mathrm{B}_{2} \mathrm{O}_{3}$, as discussed above.

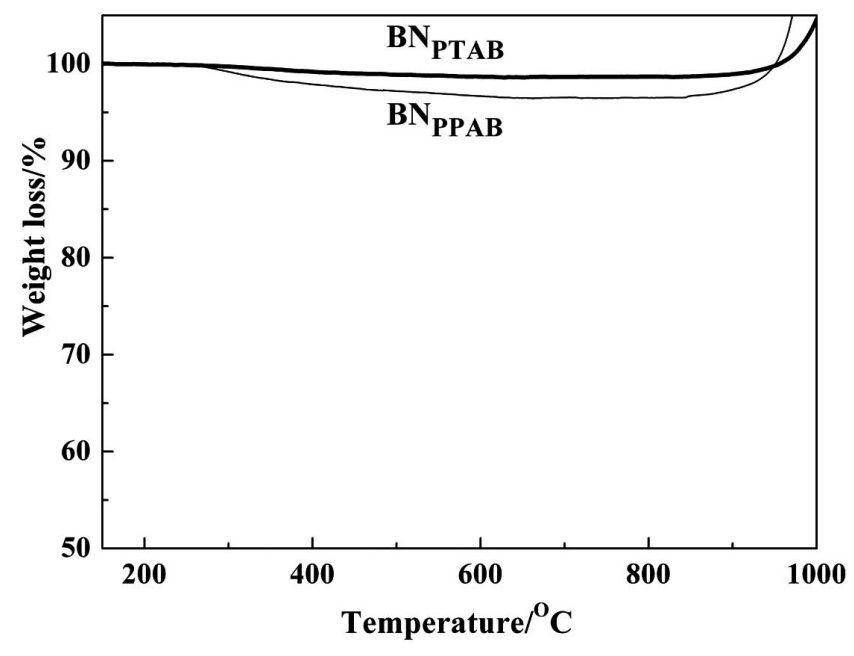

Fig. (6). TGA curves of $B N_{P T A B}$ and $B N_{P P A B}$ in flowing air.

$4 \mathrm{BN}(\mathrm{s})+3 \mathrm{O}_{2}(\mathrm{~g}) \rightarrow \mathrm{B}_{2} \mathrm{O}_{3}(\mathrm{l})+2 \mathrm{~N}_{2}(\mathrm{~g})$

$2 \mathrm{BN}(\mathrm{s})+3 \mathrm{H}_{2} \mathrm{O}(\mathrm{g}) \rightarrow \mathrm{B}_{2} \mathrm{O}_{3}(\mathrm{l})+3 \mathrm{H}_{2}(\mathrm{~g})+\mathrm{N}_{2}(\mathrm{~g})$

\section{CONCLUSIONS}

Two poly[(alkylamino)borazine]s were obtained by thermal condensation of different molecular monomers. By pyrolysis of two polymers separately, nearly stoichiometric BN samples without carbonaceous impurities were acquired. The chemical composition of both BN was similar, while the crystallinity and microstructure were different. It seems that the symmetric molecular structure gave $\mathrm{BN}$ a higher crystallinity and better oxidation resistance /high temperature stability. The present work provides a better understanding that the influence of the molecular monomer structure on high temperature properties of polymer-derived BN. 


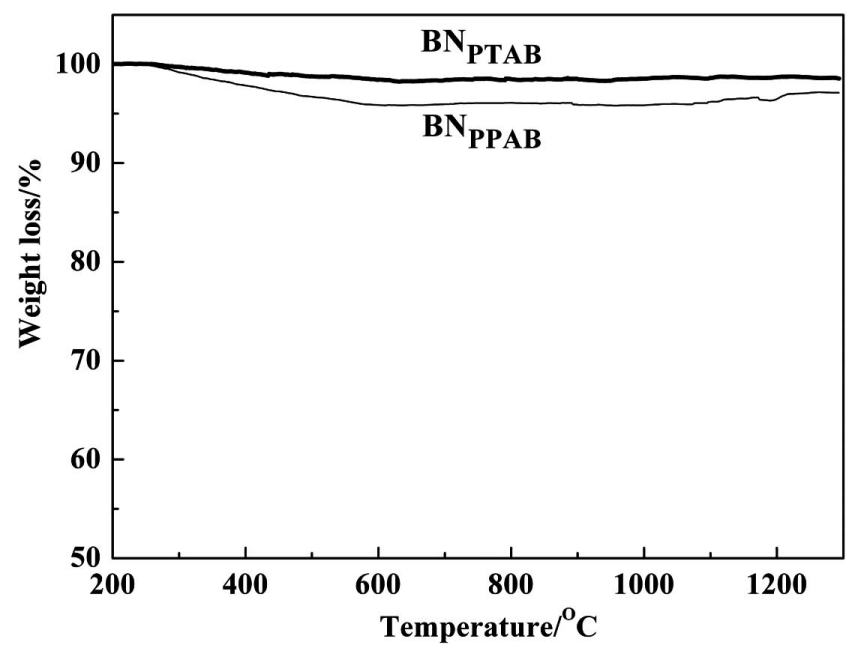

Fig. (7). TGA curves of $\mathrm{BN}_{\mathrm{PTAB}}$ and $\mathrm{BN}_{\mathrm{PPAB}}$ in flowing $\mathrm{Ar}$.

\section{ACKNOWLEDGEMENT}

The work was financially supported by National High technology Research and Development of China (No. 2006AA03A217).

\section{CONFLICTS OF INTEREST}

Declared none.

\section{REFERENCES}

[1] Paine RT, Narula CK. Synthetic routes to boron nitride. Chem Rev 1990; 90: 73-91.

[2] Li S, Bernard S, Salles V, Gervais C, Miele P. Preparation of polyborazylene-derived bulk $\mathrm{BN}$ with tunable properties by warmpressing. Chem Mater 2010; 22: 2010-7.

[3] Miele P, Bernard S, Cornu D, Tourya B. Recent developments in polymer-derived ceramic fibers (PDCFs): preparation, properties and applications - a review. Soft Mater 2007; 4: 249-86.

[4] Chu ZY, Feng CX, Song YC, Li XD, Xiao JY. Synthesis of polyborosilazane and its utilization as a precursor to boron nitride. J Appl Polym Sci 2004 ; 94 : 105-9.

[5] Tang Y, Wang J, Li XD, et al. Polymer-derived SiBN fiber for high-temperature structural/functional applications. Chemistry 2010; 16(22): 6458-62.
[6] Tang Y, Wang J, Li XD, et al. One-pot synthesis of novel polyborosilazane to SiBNC fibres. Inorg Chem Comm 2009; 12: 602-4.

[7] Deng C, Song YC, Wang YD, Li YH, Lei YP. Preparation and characterization of polymeric precursor for boron nitride fibers. Chem Res Chin Univ 2010; 31: 623-8. (In Chinese).

[8] Toury B, Bernard S, Cornu D, et al. High-performance boron nitride fibers obtained from asymmetric alkylaminoborazine. J Mater Chem 2003; 13: 274-9.

[9] Lei YP, Wang YD, Song YC, et al. Nearly stoichiometric BN fiber with low dielectric constant derived from poly[(alkylamino)borazine]. Mater Lett 2011; 65: 157-9.

[10] Toury B, Miele P, Cornu D, Vincent H, Bouix J. Boron nitride fibers prepared from asymmetric and asymmetric alkylaminoborazines. Adv Funct Mater 2002; 12: 228-34.

[11] Lei YP, Wang YD, Song YC, et al. Facile synthesis of a meltspinnable polyborazine from asymmetric alkylaminoborazine. Chin Chem Lett 2010; 21: 1079-82.

[12] Deng C, Song YC, Wang YD, et al. Synthesis of polymeric precursor for boron nitride through substitution reaction of methyalmine/dimethylamine. Acta Chim Sinica 2010; 68: 1217-22. (In Chinese).

[13] Toury B, Duriez C, Cornu D, et al. Influence of molecular precursor structure on the crystallinity of boron nitride. J Solid State Chem 2000; 154: 137-40.

[14] Lei YP, Wang YD, Song YC, et al. Effect of molecular monomer structure on the composition and properties of $\mathrm{BN}$ via the preceramic polymer route. Mater Lett 2011; 65: 1111-3.

[15] Perrin DD, Armarego WL, Perrin DR. Purification of laboratory chemicals. London: Pergamon Press 1966.

[16] Jenkins R, Snyder RL. Introduction to X-ray powder diffractometry. New York: Wiley Press 1996.

[17] Xu LQ, Peng YY, Meng ZY, et al. A co-pyrolysis method to boron nitride nanotubes at relative low temperature. Chem Mater 2003; 15: 2675-80.

[18] Jeon JK, Uchimaru Y, Kim DP. Synthesis of novel amorphous boron carbonitride ceramics from the borazine derivative copolymer via hydroboration. Inorg Chem 2004; 43: 4796-8.

[19] Rye RR, Tallant DR, Borek TT, Lindquist DA, Paine RT. Mechanistic studies of the conversion of borazine polymers to boron nitride. Chem Mater 1991; 65: 286-93.

[20] Termoss H, Toury B, Pavan S, et al. Preparation of boron nitridebased coatings on metallic substrates via infrared irradiation of dipcoated polyborazylene. J Mater Chem 2009; 19: 2671-4.

[21] Termoss H, Toury B, Brioude A, et al. High purity boron nitride thin films prepared by the PDCs route. Surf Coat Technol 2007; 201: 7822-8.

[22] Yang ZH, Jia DC, Zhou Y, et al. Oxidation resistance of hotpressed SiC-BN composites. Ceram Int 2008; 34: 317-21.

[23] Cofer CG, Economy J. Oxidation and hydrolytic stability of boron nitride - a new approach to improving the oxidation resistance of carbonaceous structures. Carbon 1995; 33: 389-95.

(C) Lei et al.; Licensee Bentham Open.

This is an open access article licensed under the terms of the Creative Commons Attribution Non-Commercial License (http://creativecommons.org/licenses/by-nc/3.0/) which permits unrestricted, non-commercial use, distribution and reproduction in any medium, provided the work is properly cited. 